\section{Dignidade humana e pacientes com esclerose lateral amiotrófica - ELA}

Regis, Arthur H. P.

Doutor em Bioética, Programa de Pós-graduação em Bioética da UnB. Professor da Faculdade Processus. Email:prof.arthur.regis@gmail.com

\author{
Castro, Cleber de ${ }^{I}$ \\ Gurgel, Caroline ${ }^{I}$ \\ Oliveira, Maurício ${ }^{I}$ \\ ${ }^{I}$ Acadêmicos da Faculdade Processus
}

PALAVRAS-CHAVE: Bioética. Esclerose Lateral Amiotrófica - ELA. Pacientes. Doenças Raras.

RESUMO: A Esclerose Lateral Amiotrófica - ELA é uma doença rara, neurodegenerativa, progressiva e incurável (com sobrevida média entre três e cinco anos), seus principais sinais e sintomas são os resultantes diretos da degeneração motoneuronal: fraqueza e atrofia, fasciculações e cãibras musculares, espasticidade, disartria, disfagia, dispneia e labilidade emocional; e os resultantes indiretos dos sintomas primários: distúrbios psicológicos, distúrbios de sono, constipação, sialorreia, espessamento de secreções mucosas, sintomas de hipoventilação crônica e dor. Entretanto, não existe um exame específico para que seja feito a caracterização da doença, levando seu diagnóstico aproximadamente um ano (uma vez que o prognóstico da doença é grave e existem muitas doenças que se manifestam de maneira similar, bem como é comum o paciente procurar uma segunda opinião médica). Por sua vez, na realidade cotidiana, os pacientes com ELA têm encontrado óbices ao acesso universal e necessário na rede de assistência, em flagrante confronto ao disposto na Lei ${ }^{\circ}$ 8.080/1990 (Lei do SUS) e ao Direito à Saúde assegurado pela Constituição Federal de 1988 (artigo 196), provocando a judicialização da questão, especialmente em um contexto no qual: a identificação da doença em seu estágio inicial e o encaminhamento ágil e adequado para o atendimento especializado dão à Atenção Básica um caráter essencial para um melhor resultado terapêutico e prognóstico dos casos; o fornecimento de ventilação mecânica (suporte ventilatório) adequado pode elevar a sobrevida do paciente para até quinze anos. Nessa conjuntura, verifica-se que a ausência de Centros de Referência para um diagnóstico mais célere e de Políticas Públicas específicas (inclusive farmacêutica) para os pacientes com ELA constituem verdadeira sentença de morte e é diretamente violadora da sua dignidade, em que pese existir a Portaria ${ }^{\circ}$ 1.370/2008 e a Portaria $n^{\circ} 370 / 2008$, ambas do Ministério da Saúde e tratando do Programa de Assistência Ventilatória Não Invasiva aos Portadores de Doenças Neuromusculares. Por sua vez, das propostas de alteração legislativa que tramitaram e tramitam no Congresso
Nacional, apenas houve a aprovação do Projeto de Lei do Senado $n^{\circ}$ 682/2015 (resultou na edição da (Lei ${ }^{\circ}$ 13.471/2017): que instituiu 21 de junho como o Dia Nacional de Luta Contra a Esclerose Lateral Amiotrófica - ELA (reconhece-se a importância do estabelecimento de um dia de conscientização e divulgação da doença, pois configura-se como importante marco, mas é necessário avançar ainda mais). Conclui-se que o Princípio da Dignidade da Pessoa Humana, pedra angular da Declaração Universal dos Direitos Humanos (Artigo 1) e fundamento da República Federativa do Brasil (inciso III do artigo $1^{\circ}$ da Constituição Federal), não resta garantido e protegido em sua integralidade no que se refere aos pacientes com ELA. Portanto, deve-se lutar pela existência de um sistema normativo mais protetivo e com efetividade máxima conjugado com a indissociável garantia da dignidade dos mais vulneráveis (pacientes com ELA), utilizando-se, para tanto, também os elementos norteadores consagrados na Declaração Universal sobre Bioética e Direitos Humanos.

AGRADECIMENTOS: À Faculdade Processus pelo apoio e fomento ao Grupo de Pesquisa "Direito à Saúde".

\section{REFERÊNCIAS}

[1] ALBUQUERQUE, A. Direitos Humanos dos Pacientes. Curitiba: Juruá, 2016.

[2] BANDEIRA, F.M. ET AL. Avaliação da qualidade de vida de pacientes portadores de Esclerose Lateral Amiotrófica (ELA) em Brasília. Revista Neurociências 2010;18(2):133-138.

[3] LIMA, M.A.F.D.; HOROVITZ, D.D.G. Contradições das políticas públicas voltadas para doenças raras: o exemplo do Programa de Tratamento da Osteogênese Imperfeita no SUS. Ciência \& Saúde Coletiva, 19(2):475-480, 2014.

[4] ROMERO. L.C. Judicialização das políticas de assistência farmacêutica: o caso do Distrito Federal. Textos para Discussão. Brasília: Senado Federal. 2012. Acesso em 24 jul. 2018. Disponível em: <http://www2.senado.leg.br/bdsf/handle/id/96829>

[5] UNESCO. The principle of respect for human vulnerability and personal integrity Report of the International Bioethics Committee of UNESCO (IBC). France: United Nations Educational, Scientific and Cultural Organization, 2013. 